\title{
Airway inflammatory markers in individuals with cystic fibrosis and non-cystic fibrosis bronchiectasis
}

\author{
David A Bergin \\ Killian Hurley \\ Adwait Mehta \\ Stephen Cox \\ Dorothy Ryan \\ Shane J O'Neill \\ Emer P Reeves* \\ Noel G McElvaney* \\ Respiratory Research Division, \\ Department of Medicine, Royal \\ College of Surgeons in Ireland, \\ Education and Research Centre, \\ Beaumont Hospital, Dublin, Ireland \\ *These authors share joint senior \\ authorship
}

This article was published in the following Dove Press journal: Journal of Inflammation Research 22 January 2013

Number of times this article has been viewed

\begin{abstract}
Bronchiectasis is an airway disease characterized by thickening of the bronchial wall, chronic inflammation, and destruction of affected bronchi. Underlying etiologies include severe pulmonary infection and cystic fibrosis (CF); however, in a substantial number of patients with non-CF-related bronchiectasis (NCFB), no cause is found. The increasing armamentarium of therapies now available to combat disease in $\mathrm{CF}$ is in stark contrast to the limited tools employed in NCFB. Our study aimed to evaluate similarities and differences in airway inflammatory markers in patients with $\mathrm{NCFB}$ and $\mathrm{CF}$, and to suggest potential common treatment options. The results of this study show that NCFB bronchoalveolar lavage fluid samples possessed significantly increased NE activity and elevated levels of matrix metalloproteinases 2 (MMP-2) and MMP-9 compared to healthy controls $(P<0.01)$; however, the levels detected were lower than in $\mathrm{CF}(P<0.01)$. Interleukin-8 (IL-8) concentrations were significantly elevated in NCFB and CF compared to controls $(P<0.05)$, but in contrast, negligible levels of IL-18 were detected in both NCFB and CF. Analogous concentrations of IL-10 and IL-4 measured in NCFB and CF were statistically elevated above the healthy control values $(P<0.05$ and $P<0.01$, respectively). These results indicate high levels of important proinflammatory markers in both NCFB and CF and support the use of appropriate anti-inflammatory therapies already employed in the treatment of CF bronchiectasis in NCFB.
\end{abstract}

Keywords: bronchiectasis, cystic fibrosis, proteases, inflammation

\section{Introduction}

Bronchiectasis is a respiratory disease characterized by dilated thick-walled bronchi, periods of acute infective exacerbations, inflammation, and purulent sputum expectoration. The cycle of infection and inflammation results in permanent lung tissue damage and remodeling. Causes or genetic conditions leading to the development of bronchiectasis include immunodeficiency, primary ciliary dyskinesia or severe pulmonary infection, but the most common cause of bronchiectasis in children is cystic fibrosis $(\mathrm{CF}){ }^{1}$

In the United States, the prevalence of non-CF-related bronchiectasis (NCFB) in the older population ( $>65$ years) now stands at 1106 cases $/ 100,000$ persons and is increasing at a rate of $8.7 \%$ per year from the year 2000 through to 2007 with consequent costs to health care delivery. ${ }^{2}$ Indeed, the prevalence and severity of NCFB intensifies with age and when in association with other diseases or autoimmune symptoms, including chronic obstructive pulmonary disease (COPD) or rheumatoid arthritis respectively, the relative risk of death increases. ${ }^{3,4}$ In COPD, bronchiectasis has been reported in $50 \%$ to $57 \%$ of patients..$^{5-7}$
Correspondence: Emer P Reeves Respiratory Research Division, Department of Medicine, Royal College of Surgeons in Ireland, Beaumont Hospital, Dublin 9, Ireland Email emerreeves@rcsi.ie 
On many levels, the pathogenesis of CF lung disease and the properties of $\mathrm{CF}$ airway secretions are comparable to those of NCFB. For example, CF is caused by mutations in the $\mathrm{CF}$ transmembrane conductance regulator chloride channel, which results in increased epithelial sodium channel (ENaC)mediated ion absorption in the superficial airway epithelial., ${ }^{89}$ In concurrence, it has been shown that some patients with idiopathic bronchiectasis carry a mutation in the $\mathrm{ENaC} \beta$ or $\gamma$ genes, resulting in a defective $\mathrm{ENaC}$ protein. ${ }^{10}$ Moreover, lower respiratory tract infections with Gram-negative bacteria including Pseudomonas aeruginosa are a major cause of morbidity and mortality among patients with CF and NCFB and are associated with worsening lung function and an excess loss in forced expiratory volume in 1 second $\left.\left(\mathrm{FEV}_{1}\right)\right)^{11,12}$ Patients with $\mathrm{CF}$ and $\mathrm{NCFB}$ experience excessive neutrophilic infiltration resulting in delivery of high levels of enzymes such as neutrophil elastase (NE) to the airways, the latter playing a pivotal role in the destruction of lung tissue. ${ }^{13,14}$ The inflammatory response within the airways is dependent upon the interplay between proinflammatory and anti-inflammatory cytokines. Proinflammatory mediators, which favor neutrophil trafficking to the bronchial lumen, include interleukin-8 (IL-8), IL-1 and tumor necrosis factor- $\alpha$ (TNF- $\alpha$ ). IL- 8 is markedly increased in CF bronchial samples ${ }^{15,16}$ and in NCFB a significant correlation has been recorded between highresolution computed tomography (HRCT) severity scores and sputum IL- 8 and TNF- $\alpha$ levels. ${ }^{17}$ In response to TNF- $\alpha$, neutrophils also release matrix metalloproteinases (MMPs), ${ }^{18}$ which have the potential to augment inflammation and cause extensive airway remodeling. ${ }^{19,20}$ Increased levels of MMP-8 and MMP-9 have been reported in bronchoalveolar lavage (BAL) fluid of both CF and NCFB subjects. ${ }^{21-24}$

Despite the reported similarities, $\mathrm{CF}$ and NCFB are quite distinct and respond differently to clinical management. For example, as high concentrations of DNA contribute to the viscosity of $\mathrm{CF}$ airway secretions, treatment with recombinant human DNase (rhDNase), an enzyme which cleaves DNA polymers, results in a significant decrease in the viscosity of mucopurulent sputum in $\mathrm{CF}^{25}$ and has demonstrated an improved in $\mathrm{FEV}_{1}{ }^{26-28}$ In contrast, in adults with idiopathic bronchiectasis, treatment with rhDNase has been shown to have a negative effect on $\mathrm{FEV}_{1}$ and has led to increased pulmonary exacerbations..$^{29,30}$

Until recently, no guidelines existed to direct the clinician to the optimum diagnosis, investigation, and treatment options available for NCFB due to the relative paucity of well-controlled clinical trials and basic science research. Even now, the lack of well-designed clinical trials concerning the management of NCFB prevents the transfer of existing treatment options for $\mathrm{CF}$ bronchiectasis for use in patients with NCFB. To date, clinical reports have focused on differences between CF or NCFB airway inflammatory markers compared to healthy control individuals, but relatively few studies have directly compared CF to NCFB. Most importantly, there is now an urgency to understand the similarities and differences between these two diseases to identify the common or different treatment options. To this end, the present study was designed to directly compare airway inflammatory markers in patients with CF to NCFB.

\section{Materials and methods Chemicals}

All chemicals and reagents were purchased from Sigma Aldrich Chemical Co, Ltd (Dublin, Ireland), unless indicated otherwise.

\section{Patient recruitment and $\mathrm{BAL}$ fluid sample collection}

Prior to recruitment, nonsmoking patients had to be exacerbationfree over the preceding 6-week period. There were $6 / 10$ and $5 / 10$ males recruited to the NCFB and CF study, respectively (Table 1). The median and interquartile range of the age was 65 (51.5-71.5) and 22.50 (20.50-26.5) years for the NCFB and CF groups, respectively. Pulmonary function tests revealed a median $\mathrm{FEV}_{1}$ of $71 \%$ (range $47 \%-95 \%$ ) in the NCFB group. In all study patients, the diagnosis of bronchiectasis was made by HRCT using well-established criteria. ${ }^{31}$

The underlying cause of NCFB was postinfectious in five patients (including pertussis infection), immunoglobulin G subclass 1 deficiency in one, and in the remaining patients no cause was identified (total $n=10$ patients). No patients were identified as having alpha-1 antitrypsin deficiency. Exclusion criteria for NCFB patients were: exacerbation of bronchiectasis in the last 6-week period; current smokers; documented history of COPD, congestive cardiac failure, or neuromuscular disorder which could lead to altered spirometry; or any inflammatory disorder associated with abnormal inflammatory markers. CF was excluded by at least two negative results of sweat tests conducted in patients with a clinical presentation compatible with $\mathrm{CF}^{32,33}$ Microbiology results showed that two patients with NCFB were positive for Moraxella catarrhalis and two for P. aeruginosa.

Inclusion criteria for the $\mathrm{CF}$ cohort of patients required a confirmed diagnosis of $\mathrm{CF}$ by sweat chloride concentrations $>60 \mathrm{mmol} / \mathrm{L}$ on at least two separate occasions and subsequent confirmatory genotyping. CF patients $(n=10)$ were heterozygous for the $\Delta \mathrm{F} 508$ mutation and illustrated a median $\mathrm{FEV}_{1}$ of $39 \%(23 \%-53 \%)$. Patients with CF were 
Table I Characteristics of patients included in BAL studies

\begin{tabular}{|c|c|c|c|}
\hline & CF & NCFB & Control \\
\hline No of subjects & 10 & 10 & 10 \\
\hline Sex, \% male/female & $50 / 50$ & $60 / 40$ & $60 / 40$ \\
\hline Age, years & $22.5(20.5-26.5)$ & 65 (5I.5-7I.5) & $25(22.5-33)$ \\
\hline $\mathrm{FEV}_{1}$, \% predicted & $40(25.5-49.5)$ & 83.5 (53.5-95) & $99(9 \mid-110)$ \\
\hline Genotype & $\Delta \mathrm{F} 508$ heterozygous & - & - \\
\hline \multicolumn{4}{|l|}{ Serum protein levels } \\
\hline Alpha-I antitrypsin $(\mathrm{mg} / \mathrm{mL})$ & $1.26(0.86-1.94)$ & $\mathrm{I} .42(\mathrm{I} .34-\mid .5 \mathrm{I})$ & - \\
\hline $\lg (6.0-15.0)$ & $18.9(\mid 3.45-18.9)$ & II (8.56-13) & - \\
\hline $\lg A(0.7-4.0)$ & $2.73(0.4 I-6.1)$ & $2.63(1.39-3.52)$ & - \\
\hline $\lg M(0.5-2.3)$ & $1.29(0.53-2.29)$ & $0.66(0.16-1.21)$ & - \\
\hline \multirow[t]{4}{*}{ Bacteriology } & $\mathrm{AF}(\mathrm{n}=3)$ & $M C(n=2)$ & - \\
\hline & PA $(n=5)$ & $\mathrm{PA}(\mathrm{n}=2)$ & \\
\hline & $A F+P A(n=1)$ & & \\
\hline & $A F+S M+S A(n=I)$ & & \\
\hline \multicolumn{4}{|l|}{ BAL cells (min-max) } \\
\hline Total cells $\times 10^{3} / \mathrm{mL}$ & $1021(196-3257)$ & $243(10-1086)$ & - \\
\hline Neutrophils (\%) & $73(60-80)$ & $67(56-88)$ & - \\
\hline Macrophages (\%) & $20(10-36)$ & $27(8-38)$ & - \\
\hline
\end{tabular}

Note: Results are expressed in medians and interquartile ranges unless otherwise stated.

Abbreviations: BAL, bronchoalveolar lavage; CF, cystic fibrosis; NCFB, non-CF bronchiectasis; FEV , forced expiratory volume in I second; Ig, immunoglobulin; AF, Aspergillus fumigatus; PA, Pseudomonas aeruginosa; SM, Stenotrophomonas maltophilia; MC, Moraxella catarrhalis; SA, Staphylococcus aureus.

colonized with Aspergillus fumigatus $(\mathrm{n}=3)$ or P. aeruginosa $(\mathrm{n}=5)$. One patient was cocolonized with $A$. fumigatus and $P$. aeruginosa and one patient with A. fumigatus, Stenotrophomonas maltophilia, and Staphylococcus aureus.

BAL fluid samples were collected from patients attending Beaumont Hospital. This study complied with the tenets of the Declaration of Helsinki and full informed consent was obtained preprocedure according to a protocol approved by the Beaumont Hospital Ethics Committee. BAL fluid was obtained from adult individuals with CF $(n=10)$, NCFB $(n=10)$, sarcoidosis $(n=10)$, or healthy control volunteers $(\mathrm{n}=10)$. BAL fluid samples $(10 \mathrm{~mL})$ were obtained by wedging the bronchoscope into the most abnormal appearing lobe identified by reviewing the HRCT images and visual inspection during bronchoscopy. Sterile normal saline was instilled into this abnormal lobe and was suctioned immediately into a trap. The sample was then split and half was sent for microbiological examination, total cell count, and differential count. The remaining half was centrifuged at $1000 \mathrm{~g}$ for 10 minutes. The resulting cell-free supernatants were aliquoted and stored frozen at $-80^{\circ} \mathrm{C}$ for subsequent analysis.

\section{Cell counts and NE activity in CF BAL fluid}

The total cell count and enumeration of neutrophil and macrophages in BAL fluid was as described previously. ${ }^{34}$ NE activity was quantified using an NE-specific substrate, $\mathrm{N}$-methoxysuccinyl-ala-ala-pro-val-p-nitroanilide (R\&D
Systems, Minneapolis, MN, USA) as described previously. ${ }^{35} \mathrm{NE}$ activity was quantified in $15 \mu \mathrm{L}$ of BAL fluid at $405 \mathrm{~nm}$. BAL fluid samples were measured for protein with Bio-Rad protein assay (Bio-Rad, Richmond, CA, USA) and NE activity among patient and healthy control samples expressed as Units (U)/ $\mu \mathrm{g}$ of BAL fluid protein.

\section{Gelatinase zymography}

Gelatin zymography was performed on BAL fluid samples as described previously. ${ }^{35}$ Protein concentration was determined and $500 \mathrm{ng}$ of BAL fluid was incubated for 10 minutes in nonreducing sample buffer $(0.25 \%[\mathrm{w} / \mathrm{v}]$ bromophenol blue, $50 \mathrm{mM}$ Tris, $\mathrm{pH} 7.5,40 \%$ [v/v] glycerol and $1 \%[\mathrm{w} / \mathrm{v}]$ sodium dodecyl sulfate $[\mathrm{SDS}])$. Samples and molecular weight markers (BioRad Precision Plus Protein Standard; Bio Rad) were electrophoresed on a 7\% SDS-polyacrylamide gel electrophoresis containing gelatin $(1 \mathrm{mg} / \mathrm{mL})$. After electrophoresis, the gels were incubated in $50 \mathrm{mM}$ Tris ( $\mathrm{pH} 7.5$ ), $5 \mathrm{mM} \mathrm{CaCl}, 1 \mu \mathrm{M} \mathrm{ZnCl}_{2}$ containing $2.5 \%(\mathrm{v} / \mathrm{v})$ Triton $\mathrm{X}-100$ for 30 minutes at room temperature. The gels were washed in the same buffer without the Triton X-100 for 5 minutes and then incubated at $37^{\circ} \mathrm{C}$ overnight in the same buffer supplemented with $1 \%(\mathrm{v} / \mathrm{v})$ Triton $\mathrm{X}-100$. To visualize gelatinases, gels were stained with Coomassie blue stain $(0.2 \%$ [w/v] Coomassie brilliant blue, $45 \%[\mathrm{v} / \mathrm{v}]$ methanol, $10 \%[\mathrm{v} / \mathrm{v}]$ acetic acid) and then destained $(25 \%[\mathrm{v} / \mathrm{v}]$ methanol, $10 \%[\mathrm{v} / \mathrm{v}]$ acetic acid). Gelatinases appeared as translucent bands on gels 
ranging from approximately $175 \mathrm{kDa}$ to $62 \mathrm{kDa}$. As previously described, bands at approximately $85 \mathrm{kDa}$ and $72 \mathrm{kDa}$ potentially representing MMP- $9{ }^{36}$ and MMP-2, ${ }^{37}$ respectively, were quantified by densitometry using the Syngene G:BOX Chemi XL gel documentation system (Syngene, Cambridge, UK).

\section{Quantification of BAL fluid cytokine levels}

Concentrations of IL-8, IL-18, IL-10, and IL-4 in BAL fluid samples were measured by ELISA (R\&D Systems). Cytokine concentrations were expressed as $\mathrm{pg} / \mathrm{mg}$ of BAL fluid protein.

\section{Statistical analysis}

The data were analyzed with GraphPad Prism (version 4.03 for Windows; GraphPad Software, San Diego, CA, USA) and results are expressed as median value. The groups were compared by two-tailed independent sample Student's $t$-test when normally distributed or by the nonparametric MannWhitney $U$ test, as appropriate. A $P$-value $<0.05$ was deemed statistically significant.

\section{Results}

\section{Comparative quantification of $\mathrm{NE}$ activity in CF, NCFB, and healthy control BAL fluid samples}

Quantification of NE activity by fluorometric analysis revealed a significant difference in NE activity between all three groups $(P<0.01)$, with the highest level detected in BAL fluid from patients with CF $\left(110.2 \times 10^{4} \mathrm{U} / \mu \mathrm{g}\right.$ BAL fluid) (Figure 1). BAL fluid samples from individuals with NCFB illustrated an intermediate level elevated above the healthy control values $\left(9.312 \times 10^{4}\right.$ and $1.5 \times 10^{4} \mathrm{U} / \mu \mathrm{g}$ BAL fluid respectively; $P<0.01)$, but also statistically lower than the $\mathrm{CF}$ cohort $(P<0.01)$. In line with these results, NCFB BAL fluid contained a significantly lower number of neutrophils compared to $\mathrm{CF}\left(162 \times 10^{3} / \mathrm{mL}\right.$ compared to $745 \times 10^{3} / \mathrm{mL}$, respectively; $\left.P<0.01\right)$.

\section{Increased MMP-2 and MMP-9 levels in CF and NCFB BAL fluid samples}

Previous studies have demonstrated the impact of NE on MMP-2 expression ${ }^{38}$ and a correlation exists between MMP-9 and NE activity. ${ }^{23}$ This led us to evaluate MMP-2 and MMP-9 levels in bronchoalveolar samples by zymography. Representative SDS-PAGE zymograms indicating BAL fluid

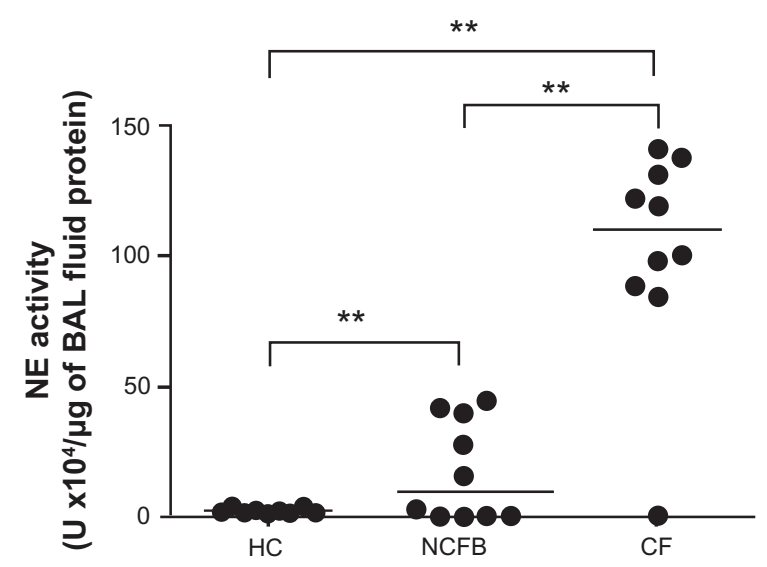

Figure I Comparative quantification of neutrophil elastase (NE) activity in CF and NCFB BAL fluid.

Notes: NE activity levels in BAL fluid of healthy control volunteers $(n=10)$, patients with CF $(n=10)$ and NCFB $(n=10)$ were compared. Individual points are from separate subjects $(* * P<0.0 \mathrm{I})$ and horizontal bars represent median values. NE activity was significantly increased in CF and NCFB compared to healthy control samples.

Abbreviations: BAL, bronchoalveolar lavage; $\mathrm{CF}$, cystic fibrosis; $\mathrm{HC}$, healthy control volunteers; NCFB, non-CF bronchiectasis; NE, neutrophil elastase.

gelatinase levels in healthy control volunteers, NCFB or CF are shown in Figure 2A-C. Results of densitometry analysis of a $72 \mathrm{kDa}$ gelatinase band, assumed to represent MMP-2 (Figure 2D) and an $85 \mathrm{kDa}$ band, potentially MMP-9 (Figure 2E), are indicated in the respective scatter plots. Statistically significant differences in median relative BAL fluid MMP-2 levels were observed in CF and NCFB in comparison to healthy control volunteers $(85.8,16.8$, and 0.40 , respectively; $P<0.01)$. The difference in median relative BAL fluid MMP-2 levels between NCFB and CF was also statistically significant $(P<0.01)$. Median relative BAL fluid MMP-9 levels were higher in CF (101.5) and NCFB (65.78) in comparison to healthy control volunteers $(0.74)$, and were also statistically different from each other $(P<0.01)$. Collectively these results provide evidence for dysregulated MMP-2 and MMP-9 levels in NCFB, albeit at a level lower to that detected in CF.

\section{Comparative quantification of IL-8 and IL- 8 in CF and NCFB BAL fluid samples}

NE has been shown to upregulate proinflammatory cytokines including IL-8 expression and secretion from bronchial epithelial cells $\mathrm{s}^{39,40}$ and negatively impact IL-18 protein integrity. ${ }^{16}$ For this reason we compared the levels of IL-8 and IL-18 in CF and NCFB BAL fluid. IL-8 measurements by ELISA revealed statistically significant differences in median BAL fluid IL-8 concentrations in CF (400.5 pg/mg of BAL fluid) and NCFB (282.3 pg/mg of BAL fluid) when compared to healthy control volunteers $(P<0.01$ and 


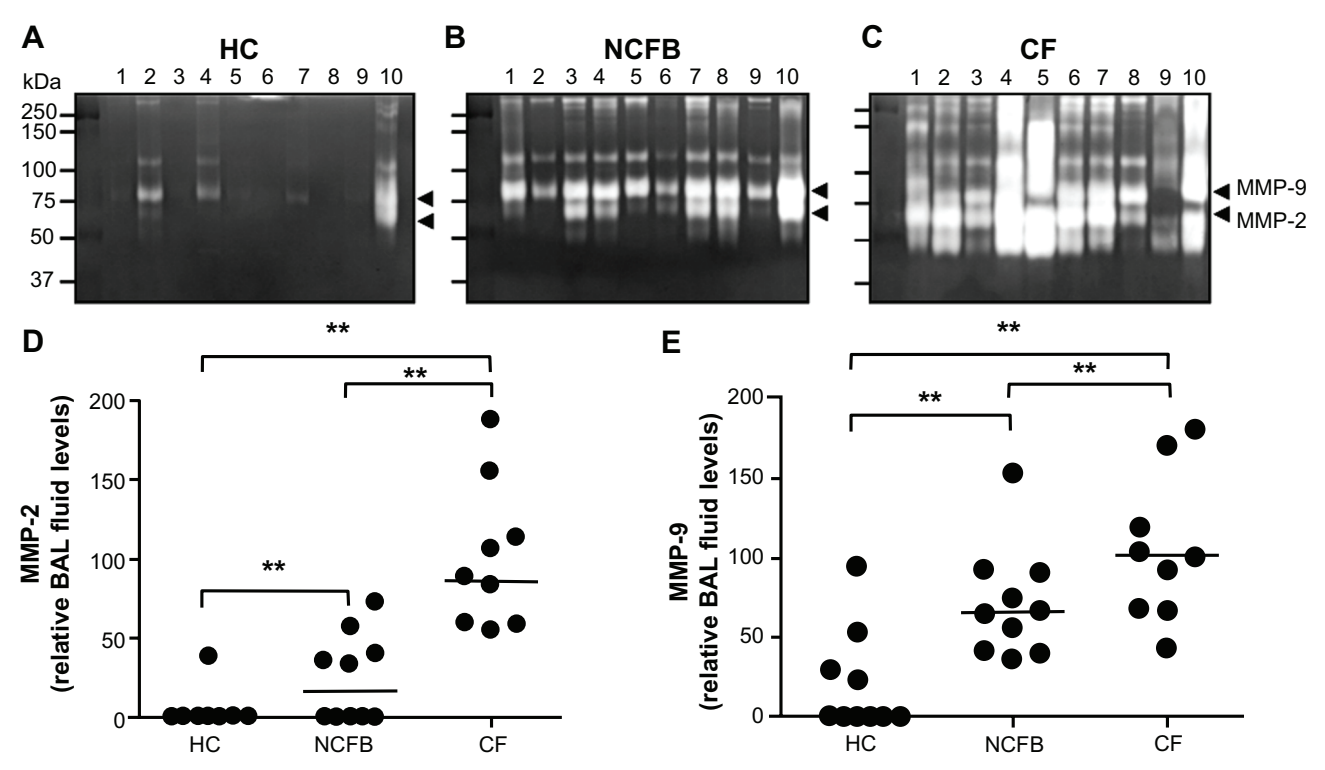

Figure 2 MMP-2 and MMP-9 levels in CF and NCFB BAL fluid. (A-C) Gelatinase levels in BAL fluid from healthy controls $(\mathbf{A} ; \mathrm{HC}, \mathrm{n}=10), \mathrm{NCFB}(\mathbf{B}, \mathrm{n}=10)$ and patients with CF $(C, n=10)$ were compared, with each lane representing BAL fluid from a separate subject. BioRad Precision Plus Protein Standard was electrophoresed and is indicated on the left. Putative MMP-9 $(85 \mathrm{kDa})$ and MMP-2 $(72 \mathrm{kDa})$ bands are indicated by the arrows. Results of densitometry analysis of MMP-2 (D) and MMP-9 (E) levels are indicated in the respective scatter plot $(* * P<0.01)$.

Note: MMP-2 and MMP-9 were significantly increased in CF and NCFB compared to healthy control samples.

Abbreviations: BAL, bronchoalveolar lavage; CF, cystic fibrosis; HC, healthy control volunteers; MMP, matrix metalloproteinase; NCFB, non-CF bronchiectasis.

$P<0.05$, respectively). The difference in median BAL fluid concentrations of IL- 8 between NCFB and CF was also statistically significant $(P<0.05)$. This set of experiments demonstrates that IL-8 levels in NCFB are at a level intermediate to the healthy control and $\mathrm{CF}$ groups. In contrast, $\mathrm{CF}$ and NCFB BAL fluid IL-18 levels were consistently low and no significant difference was observed when compared to the healthy control volunteers (Figure 3B). As a positive control for this experiment BAL fluid from parents with sarcoidosis was employed, as this has previously been shown to contain high levels of IL-18. ${ }^{41}$

\section{IL-I0 and IL-4 protein levels are similar in CF and NCFB BAL fluid samples}

Previous studies have revealed the prevalence of high levels of anti-inflammatory cytokines within the CF airways. ${ }^{42,43}$ Consequently, we next compared the levels of IL-10 and IL-4 in CF BAL fluid to NCFB samples. Results of ELISA analysis of IL-10 and IL-4 are indicated in Figure 4. Statistically significant differences in BAL fluid IL-10 median levels were observed in $\mathrm{CF}$ and NCFB in comparison to healthy control volunteers $(75.62,151.3$, and $0.1 \mathrm{pg} / \mathrm{mg}$, respectively; $P<0.05$ ) (Figure 4A). The difference in IL-10 levels
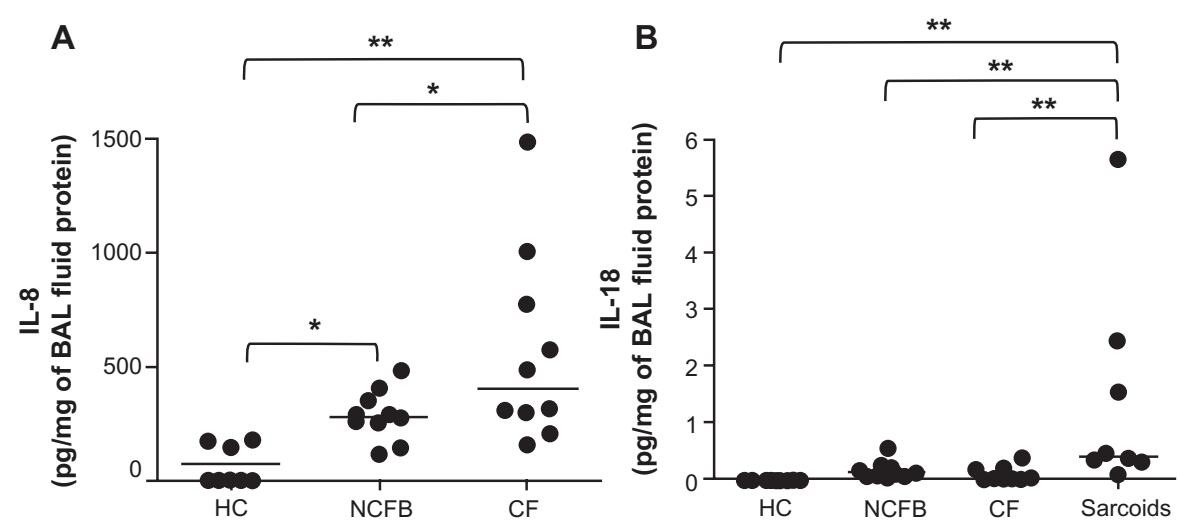

Figure 3 IL-8 and IL-I 8 levels in BAL fluid. BAL fluid proinflammatory IL-8 (A) and IL-I8 (B) concentrations were determined by sandwich ELISA.

Notes: Patients with CF $(n=10)$, NCFB $(n=10)$, sarcoidosis (sarcoids, $n=8)$, and healthy control volunteers $(H C, n=10)$ were compared in the respective ELISAs. Sarcoidosis samples were used as a positive control for the IL-I8 ELISA. All values points are from separate subjects $(* P<0.05 ; * * P<0.0 I)$ and $p r e s e n t e d$ as $P g / m g$ of $B A L$ fluid protein. Horizontal bars represent median values.

Abbreviations: BAL, bronchoalveolar lavage; CF, cystic fibrosis; HC, healthy control volunteers; IL, interleukin; NCFB, non-CF bronchiectasis. 

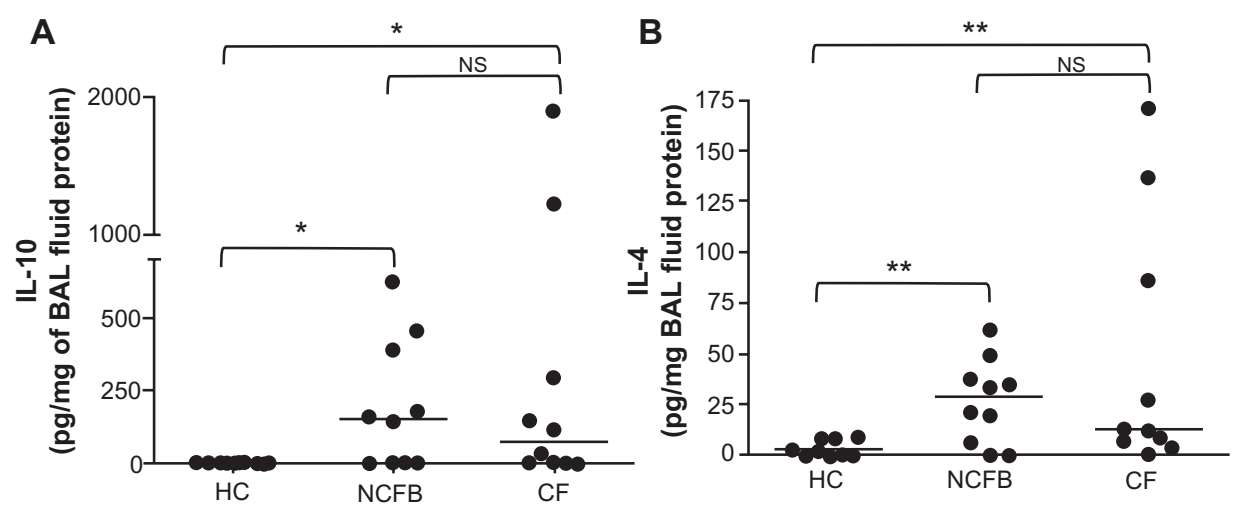

Figure 4 IL- 10 and IL-4 levels in BAL fluid.

Notes: BAL fluid anti-inflammatory IL-I0 and IL-4 concentrations were determined by sandwich ELISA. All value points from patients with CF ( $\mathrm{n}=\mathrm{I0}$ ), NCFB ( $\mathrm{n}=\mathrm{I0}$ ), and healthy control volunteers $(n=10)$ were compared. Data are presented as $\mathrm{pg} / \mathrm{mg}$ of BAL fluid protein $(* P<0.05 ; * * P<0.01)$ and horizontal bars represent median values. Levels of IL- 10 and IL-4 are similar in CF and NCFB.

Abbreviations: BAL, bronchoalveolar lavage; CF, cystic fibrosis; HC, healthy control volunteers; IL, interleukin; NCFB, non-CF bronchiectasis; NS, nonsignificant.

between NCFB and CF was not statistically significant $(P=0.9)$. Median BAL fluid IL-4 levels were higher in $\mathrm{CF}$ $(12.55 \mathrm{pg} / \mathrm{mg})$ and NCFB $(28.38 \mathrm{pg} / \mathrm{mg})$ compared to healthy control samples $(2.12 \mathrm{pg} / \mathrm{mg})$, but were not statistically different from each other $(P=0.9)$ (Figure 4B). Collectively these data indicate that in contrast to disproportionate levels of proteases and proinflammatory IL-8 levels (Figures 1-3), these results provide evidence for analogous concentrations of anti-inflammatory cytokines including IL-4 and IL-10 in NCFB and CF bronchial samples.

\section{Correlation of NE and MMP-9 with FEV, in CF and NCFB BAL fluid samples}

Many studies have shown reduced $\mathrm{FEV}_{1}$ to be associated with increased inflammatory markers in respiratory diseases. ${ }^{44} 47$ Our study compares two diseases with similar manifestations but with different pathogenesis and this dichotomy is evident when we look at the result of NE with respect to $\mathrm{FEV}_{1}$ (Figure 5A). Individuals with NCFB clearly have higher median $\mathrm{FEV}_{1}(83.5 \%$ versus $40 \%$ in $\mathrm{CF}$ ) in association with greatly reduced median NE when compared with CF. In fact the median NE is reduced by a factor of approximately ten times in the NCFB compared to the CF group defining a separate region in the graphic $\left(110.2 \times 10^{4}\right.$ versus $9.312 \times 10^{4} \mathrm{U} / \mu \mathrm{g}$ BAL fluid). Nevertheless there is a poor, but statistically significant, correlation of $\mathrm{NE}$ with declining $\mathrm{FEV}_{1}\left(\mathrm{r}^{2}=0.2660 ; P=0.01\right)$. This difference in NE may be explained by the difference in the total neutrophil number seen in NCFB BAL fluid compared to CF (Table 1). When we examine the relationship between $\mathrm{FEV}_{1}$ and the neutrophilderived MMP-9, a similar, but not as marked, separation is evident, with NCFB demonstrating higher FEV , with lower MMP-9 than CF BAL fluid (Figure 5B). A significant correlation between falling FEV 1 and increasing MMP-9 exists $\left(\mathrm{r}^{2}=0.4646 ; P=0.01\right)$ which is likely a surrogate marker of the degree of severity of illness and frequency of exacerbation in $\mathrm{CF}$ over that seen in NCFB.

\section{Discussion}

In this study, we evaluated the levels of airway inflammatory markers in adults with $\mathrm{CF}$ and NCFB. The results indicate high levels of inflammatory markers in both CF and NCFB airway samples and although divergent activity of proteases and proinflammatory IL-8 levels were detected, which may be explained by neutrophil number and severity of disease, respectively, comparable levels of the anti-inflammatory cytokines IL-10 and IL-4 were present in CF and NCFB bronchial samples.

The airway microbiome within the CF and NCFB milieu involves recognized pathogens such as $P$. aeruginosa, ${ }^{11,12,48}$ Streptococcus pneumoniae, Haemophilus influenzae, ${ }^{49}$ $S$. maltophilia, and $S$. aureus and/or colonization by the filamentous fungi A. fumigatus. ${ }^{50}$ Bacterial-released enzymes including Pseudomonas pseudolysin (elastase) and aeruginolysin (alkaline protease) have been shown to proteolytically cleave and inactivate the antiprotease elafin ${ }^{51}$ and to completely degrade IL-18. ${ }^{16}$ However, the presence of inflammation in the absence of detectable microbes in the $\mathrm{CF}^{52}$ and $\mathrm{NCFB}^{14}$ airways has also been described. Indeed, six of the $10 \mathrm{NCFB}$ patients recruited to this study were free from microbial colonization, yet presented with high levels of NE-enhanced inflammation. Although lower levels of NE activity were detected in samples of BAL fluid from NCFB compared to CF individuals, within the airways the persistently dominant activity of NE can lead to degradation of structural matrix proteins including elastin, 

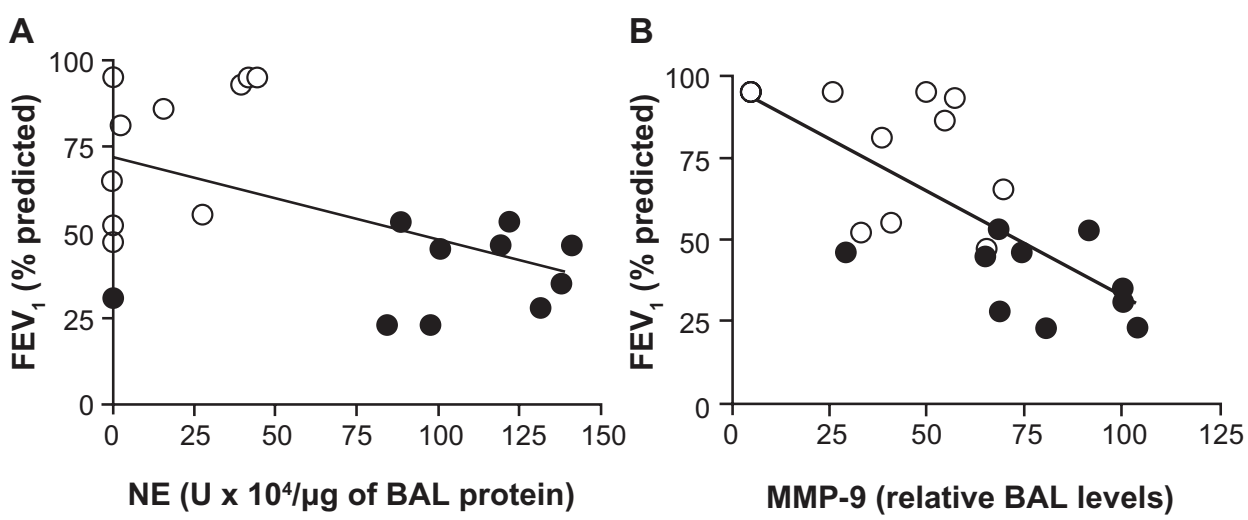

Figure 5 Correlation between NE activity and MMP-9 levels with FEV, Correlation between NE activity $(\mathbf{A})$ or MMP-9 levels (B) and FEV in CF $(\bullet)$ and NCFB $(\circ)$. (A) A significant correlation of NE with declining FEV $\left(r^{2}=0.2660, P=0.01\right)$ was observed. (B) A significant correlation between declining FEV, and MMP-9 was recorded $\left(r^{2}=0.4646, P=0.01\right)$.

Abbreviations: BAL, bronchoalveolar lavage; CF, cystic fibrosis; FEV , forced expiratory volume in I second; HC, healthy control volunteers; MMP, matrix metalloproteinase; NCFB, non-CF bronchiectasis; NE, neutrophil elastase.

collagen, and proteoglycans. ${ }^{13}$ As demonstrated in this study (Figure 5A), NE concentrations in NCFB sputum have been shown to correlate positively with neutrophil cell numbers ${ }^{14}$ and negatively with lung function in $\mathrm{CF}$ and NCFB. ${ }^{53}$ Our study illustrates two distinct patterns of NE in NCFB and CF BAL fluid, which may be explained by the difference in total neutrophil numbers. The decreased neutrophil number in our NCFB BAL fluid samples could in turn lead to reduced neutrophil-derived DNA in the airway, in part clarifying the previously described lack of successful treatment of NCFB with rhDNase. ${ }^{30}$

In this paper, we also compared the presence of two MMPs in BAL samples, with MMP-9 and MMP-2 levels in NCFB illustrating an intermediate range between those detected in $\mathrm{CF}$ and healthy control samples. These data are in contrast to a previous study that found no significant difference in the level of MMP-9 in exhaled breath condensate of children with CF compared to NCFB. ${ }^{54}$ This variance in results is possibly due to the zymographic detection of gelatinase levels in BAL fluid in our study, compared to the use of ELISA in the study by Karakoc et al. ${ }^{54}$ Indeed, both MMP-9 and MMP-2 are secreted as an inactive proform and a role for neutrophil-derived serine proteases in their activation has been described. ${ }^{23,55} \mathrm{~A}$ previous study has established a strong correlation between NE and MMP-9 activity in CF samples ${ }^{23}$ and incubation of human HT-1080 cells with either NE, cathepsin $\mathrm{G}$ or proteinase- 3 resulted in pro-MMP-2 activation, an effect reversed by inclusion of the serine protease inhibitor alpha-1 antitrypsin. ${ }^{55}$ When we examined the relationship of $\mathrm{FEV}_{1}$ to the neutrophil-derived MMP-9 (Figure 5B), a clear correlation of increasing MMP-9 levels with falling FEV was observed. Moreover, MMP-2 has been implicated in the pathogenesis of a number of pulmonary disorders including
COPD and asthma. ${ }^{56}$ Recently we have demonstrated that NE can augment MMP-2 expression, potentially leading to an increased inflammatory response within the CF airways, with important implications for antiprotease therapeutic intervention. $^{38}$

A number of comprehensive studies have evaluated the cytokine profile, including IL-8 levels in lungs of children and adults with $\mathrm{CF}^{42,57}$ Compared to healthy control volunteers, within the present study we found that IL-8 concentrations are elevated in both CF and NCFB airway samples, although a significant difference was apparent between the two patient groups with lower levels detected in NCFB. The levels of IL-8 detected in NCFB compared to healthy controls is in agreement with a previous report demonstrating a positive correlation between sputum IL-8 levels and NCFB symptom scores, and a negative correlation with lung function. ${ }^{17}$ Of interest, a recent study found no significant difference in sputum IL-8 levels in NCFB patients who were either Pseudomonas colonized or noncolonized, suggesting IL-8 as a potential target for anticytokine therapy. ${ }^{14}$ Moreover, excessive neutrophilic inflammation in CF is partially explained by the stability of IL- 8 within the lung. The aforementioned stability has been attributed to the capacity of IL-8 to bind glycosaminoglycans, which are overexpressed within the $\mathrm{CF}$ airways, ${ }^{58-62}$ although a similar phenomenon in NCFB has yet to be explored. Hypertonic saline is now a cornerstone of airway clearance therapy in CF and until recently has been considered primarily as an airway hydration therapy. However, a new mechanistic study has shown that hypertonic saline also posseses immunomodulatory properties as it disrupts the interaction between glycosaminoglycans and IL-8, rendering IL-8 more susceptible to proteolytic degradation, thus helping to resolve inflammation in the airway. ${ }^{63}$ In this 
light, the use of hypertonic saline in NCFB appears to hold great promise as the present study shows that the airways hold similar increased levels of IL-8 to CF bronchiectasis.

In contrast to IL-8, IL-18 binds poorly to glycosaminoglycans and is highly sensitive to proteolytic degradation. ${ }^{16}$ Reduced IL-18 protein levels have previously been described in CF BAL fluid samples ${ }^{16,64,65}$ and it has been reported that IL-18 degradation and clearance occurs within minutes after exposure to serine proteases including NE and cathepsin G. ${ }^{16}$ The susceptibility of IL-18 to serine protease degradation may explain why no IL-18 was detected in NCFB BAL fluid. Reduced $\mathrm{T}_{\mathrm{H}} 1$ response to microbial infection has been correlated with IL-18 deficiency ${ }^{66}$ and hence this study suggests that a strategy leading to a reduction in levels of serine protease activity, such as nebulized antiproteases, ${ }^{67}$ may positively affect IL-18 stability and improve the pulmonary outcome of microbial-infected CF and NCFB individuals. Indeed, the concept of strategies which decrease serine protease activity has had some initial success in CF bronchiectasis where inhalation of alpha-1 antitrypsin over 4 weeks has been shown not only to reduce free elastase, but also the proinflammatory mediators IL-8, TNF- $\alpha$, IL-1 $\beta$, and $\mathrm{LTB}_{4} \cdot{ }^{68}$

The biological activity of IL-4 and the $\mathrm{T}_{\mathrm{H}} 2$ bias of CF lymphocytes have been comprehensively studied by a number of investigators. ${ }^{43,69}$ Within the present study we observed that IL-4 is equally expressed at high levels in CF and NCFB BAL fluid compared to healthy control samples. As pulmonary protein levels of IL-4 have previously been shown to inversely correlate with lung function in $\mathrm{CF}^{43}$ these findings may have implications for patients with NCFB. IL-10 is also an important anti-inflammatory mediator that functions to inhibit production of cytokines by $\mathrm{T}$ lymphocytes, modulates IL-8 production by macrophages, and promotes resolution of lung inflammation by promoting neutrophil apoptosis. Within this study, we observed equal protein expression of IL-10 in CF and NCFB, with recorded levels statistically increased above the median of the healthy control. This result is in contrast to those demonstrating that IL-10 was significantly depressed and differed little from healthy controls. ${ }^{43}$ However, our data are supported by two other studies which demonstrated significantly higher levels of IL-10 present in BAL fluid ${ }^{42}$ and sera ${ }^{65}$ from infected and uninfected patients with $\mathrm{CF}$ when compared to either pristine or disease control subjects.

A number of limitations to this study should be discussed. Firstly, the differences observed between CF and NCFB in this study may in part be explained by the greatly reduced $\mathrm{FEV}_{1}$, extent or severity of bronchiectasis, and the presence of airway bacterial colonization including $P$. aeruginosa infection present in the CF lung. Secondly, the patient number recruited is small due to strict inclusion and exclusion criteria and single-hospital nature of this study and the patients are not well matched for age. The above factors may limit the generalizability of the study results and conclusions. Larger multicenter studies looking at airway inflammatory markers in the two diseases and randomized controlled trials of specific therapies are required. Thirdly, BAL samples were acquired from the most affected lobe identified by HRCT and visual inspection for both the $\mathrm{CF}$ and NCFB groups, given that it is well recognized that inflammation and severity of disease are heterogeneous in NCFB the results may reflect the worst case scenario for inflammation in NCFB rather than reflect the whole lung condition as seen in the more homogenous inflammation observed in CF bronchiectasis.

Despite these limitations however, many similarities in inflammatory markers exist, which suggests that the existing strategy of transferring therapies from the $\mathrm{CF}$ population to the NCFB population carries significant merit despite the obvious exception of rhDNase. ${ }^{30}$ Further work is suggested by this study, for example a prospective assessment of inflammatory markers before and after $P$. aeruginosa eradication to elucidate the pathogenesis of this important pathogen. Azithromycin, a macrolide antibiotic and wellestablished treatment for patients with CF bronchiectasis who are colonized with Pseudomonas is now emerging as a treatment for COPD, asthma, and bronchiolitis obliterans where it is used as a novel anti-inflammatory. ${ }^{70-74}$ Indeed a recently published study by Wong et al, does suggest that azithromycin treatment may prove beneficial in the prevention of exacerbations in individuals with NCFB. ${ }^{75}$ In contrast to $\mathrm{CF}, \mathrm{FEV}_{1}$ in $\mathrm{NCFB}$ remains a poor indicator of disease response to treatment; therefore along with patient related outcomes, time to exacerbation and number of exacerbations, airway proinflammatory cytokine release may find a place as a surrogate marker of successful treatment. In conclusion, these data suggest that therapeutic strategies pertinent to $\mathrm{CF}$ bronchiectasis, including anti-inflammatory therapies, are of potential benefit in treatment of NCFB.

\section{Acknowledgments}

Preparation of this article was supported in part by grants from Science Foundation Ireland (grant number 11/RFP/ BMT/3094), The Medical Research Charities Group/ Health Research Board, The US Alpha One Foundation and the Program for Research in Third Level Institutes 
(PRTLI) administered by the Higher Education Authority. In addition, the authors would like to thank all patients and healthy donors who participated in this study. Conception, analysis, and interpretation of experimental results: DR, $\mathrm{KH}, \mathrm{AM}, \mathrm{SC}$, SJO'N, and DAB; drafting of manuscript: EPR, KH and NGM.

\section{Disclosure}

None of the authors have a financial relationship with a commercial entity that has an interest in the subject of the presented manuscript.

\section{References}

1. Bilton D. Update on non-cystic fibrosis bronchiectasis. Curr Opin Pulm Med. 2008;14(6):595-599.

2. Seitz AE, Olivier KN, Adjemian J, Holland SM, Prevots DR. Trends in bronchiectasis among Medicare beneficiaries in the United States, 2000-2007. Chest. 2012;142(2):432-439.

3. Keistinen T, Saynajakangas O, Tuuponen T, Kivela SL. Bronchiectasis: an orphan disease with a poorly understood prognosis. Eur Respir J. 1997;10(12):2784-2787.

4. Swinson DR, Symmons D, Suresh U, Jones M, Booth J. Decreased survival in patients with co-existent rheumatoid arthritis and bronchiectasis. Br J Rheumatol. 1997;36(6):689-691.

5. Martinez-Garcia MA, Soler-Cataluna JJ, Donat Sanz Y, et al. Factors associated with bronchiectasis in patients with COPD. Chest. 2011;140(5):1130-1137.

6. O’Brien C, Guest PJ, Hill SL, Stockley RA. Physiological and radiological characterisation of patients diagnosed with chronic obstructive pulmonary disease in primary care. Thorax. 2000;55(8): 635-642.

7. Patel IS, Vlahos I, Wilkinson TM, et al. Bronchiectasis, exacerbation indices, and inflammation in chronic obstructive pulmonary disease. Am J Respir Crit Care Med. 2004;170(4):400-407.

8. Boucher RC, Stutts MJ, Knowles MR, Cantley L, Gatzy JT. Na+ transport in cystic fibrosis respiratory epithelia. Abnormal basal rate and response to adenylate cyclase activation. $J$ Clin Invest. 1986;78(5):1245-1252.

9. Stutts MJ, Canessa CM, Olsen JC, et al. CFTR as a cAMP-dependent regulator of sodium channels. Science. 1995;269(5225):847-850.

10. Fajac I, Viel M, Sublemontier S, Hubert D, Bienvenu T. Could a defective epithelial sodium channel lead to bronchiectasis? Respir Res. 2008;9:46

11. Saiman L, Marshall BC, Mayer-Hamblett N, et al. Azithromycin in patients with cystic fibrosis chronically infected with Pseudomonas aeruginosa: a randomized controlled trial. JAMA. 2003;290(13): 1749-1756.

12. Martinez-Garcia MA, Soler-Cataluna JJ, Perpina-Tordera M, Roman-Sanchez P, Soriano J. Factors associated with lung function decline in adult patients with stable non-cystic fibrosis bronchiectasis. Chest. 2007;132(5):1565-1572.

13. Kelly E, Greene CM, McElvaney NG. Targeting neutrophil elastase in cystic fibrosis. Expert Opin Ther Targets. 2008;12(2) $145-157$.

14. Tsang KW, Chan K, Ho P, et al. Sputum elastase in steady-state bronchiectasis. Chest. 2000;117(2):420-426.

15. Muhlebach MS, Noah TL. Endotoxin activity and inflammatory markers in the airways of young patients with cystic fibrosis. Am J Respir Crit Care Med. 2002;165(7):911-915.

16. Reeves EP, Williamson M, Byrne B, et al. IL-8 dictates glycosaminoglycan binding and stability of IL-18 in cystic fibrosis. $J$ Immunol. 2010;184(3):1642-1652.
17. Guran T, Ersu R, Karadag B, et al. Association between inflammatory markers in induced sputum and clinical characteristics in children with non-cystic fibrosis bronchiectasis. Pediatr Pulmonol. 2007;42(4): 362-369.

18. O'Connor CM, FitzGerald MX. Matrix metalloproteases and lung disease. Thorax. 1994;49(6):602-609.

19. Heppner KJ, Matrisian LM, Jensen RA, Rodgers WH. Expression of most matrix metalloproteinase family members in breast cancer represents a tumor-induced host response. Am J Pathol. 1996;149(1): 273-282.

20. Jackson PL, Xu X, Wilson L, et al. Human neutrophil elastase-mediated cleavage sites of MMP-9 and TIMP-1: Implications to cystic fibrosis proteolytic dysfunction. Mol Med. 2010;16(5-6):159-166.

21. Sepper R, Konttinen YT, Ding Y, Takagi M, Sorsa T. Human neutrophil collagenase (MMP-8), identified in bronchiectasis BAL fluid, correlates with severity of disease. Chest. 1995;107(6): 1641-1647.

22. Sepper R, Konttinen YT, Sorsa T, Koski H. Gelatinolytic and type IV collagenolytic activity in bronchiectasis. Chest. 1994;106(4): 1129-1133.

23. Gaggar A, Li Y, Weathington N, et al. Matrix metalloprotease-9 dysregulation in lower airway secretions of cystic fibrosis patients. Am J Physiol Lung Cell Mol Physiol. 2007;293(1):L96-L104.

24. Ratjen F, Hartog CM, Paul K, Wermelt J, Braun J. Matrix metalloproteases in BAL fluid of patients with cystic fibrosis and their modulation by treatment with dornase alpha. Thorax. 2002;57(11):930-934.

25. Shak S, Capon DJ, Hellmiss R, Marsters SA, Baker CL. Recombinant human DNase I reduces the viscosity of cystic fibrosis sputum. Proc Natl Acad Sci U S A. 1990;87(23):9188-9192.

26. Fuchs HJ, Borowitz DS, Christiansen DH, et al. Effect of aerosolized recombinant human DNase on exacerbations of respiratory symptoms and on pulmonary function in patients with cystic fibrosis. The Pulmozyme Study Group. N Engl J Med. 1994;331(10):637-642.

27. Ramsey BW, Astley SJ, Aitken ML, et al. Efficacy and safety of short-term administration of aerosolized recombinant human deoxyribonuclease in patients with cystic fibrosis. Am Rev Respir Dis. 1993;148(1):145-151.

28. Ranasinha C, Assoufi B, Shak S, et al. Efficacy and safety of short-term administration of aerosolised recombinant human DNase I in adults with stable stage cystic fibrosis. Lancet. 1993;342(8865):199-202.

29. Kristensen K. Recombinant human DNase in conditions other than cystic fibrosis. Ugeskr Laeger. 2010;172(8):616-619.

30. O'Donnell AE, Barker AF, Ilowite JS, Fick RB. Treatment of idiopathic bronchiectasis with aerosolized recombinant human DNase I. rhDNase Study Group. Chest. 1998;113(5):1329-1334.

31. Naidich DP, McCauley DI, Khouri NF, Stitik FP, Siegelman SS. Computed tomography of bronchiectasis. J Comput Assist Tomogr. 1982;6(3):437-444.

32. Ooi CY, Dupuis A, Ellis L, et al. Comparing the American and European diagnostic guidelines for cystic fibrosis: same disease, different language? Thorax. 2012;67(7):618-624.

33. Pasteur MC, Bilton D, Hill AT. British Thoracic Society guideline for non-CF bronchiectasis. Thorax. 2010;65 Suppl 1:i1-i58.

34. Bergsson G, Reeves EP, McNally P, et al. LL-37 complexation with glycosaminoglycans in cystic fibrosis lungs inhibits antimicrobial activity, which can be restored by hypertonic saline. J Immunol. 2009;183(1):543-551.

35. Bergin DA, Greene CM, Sterchi EE, et al. Activation of the epidermal growth factor receptor (EGFR) by a novel metalloprotease pathway. J Biol Chem. 2008;283(46):31736-31744.

36. Montano M, Beccerril C, Ruiz V, Ramos C, Sansores RH, GonzalezAvila G. Matrix metalloproteinases activity in COPD associated with wood smoke. Chest. 2004;125(2):466-472.

37. Geraghty P, Rogan MP, Greene CM, et al. Alpha-1-antitrypsin aerosolised augmentation abrogates neutrophil elastase-induced expression of cathepsin B and matrix metalloprotease 2 in vivo and in vitro. Thorax. 2008;63(7):621-626. 
38. Geraghty P, Rogan MP, Greene CM, et al. Neutrophil elastase up-regulates cathepsin B and matrix metalloprotease-2 expression. J Immunol. 2007;178(9):5871-5878.

39. Devaney JM, Greene CM, Taggart CC, Carroll TP, O’Neill SJ, McElvaney NG. Neutrophil elastase up-regulates interleukin-8 via toll-like receptor 4. FEBS Lett. 2003;544(1-3):129-132.

40. Walsh DE, Greene CM, Carroll TP, et al. Interleukin-8 up-regulation by neutrophil elastase is mediated by MyD88/IRAK/TRAF-6 in human bronchial epithelium. J Biol Chem. 2001;276(38):35494-35499.

41. Greene CM, Meachery G, Taggart CC, et al. Role of IL-18 in CD4+ T lymphocyte activation in sarcoidosis. J Immunol. 2000; 165(8):4718-4724.

42. Armstrong DS, Hook SM, Jamsen KM, et al. Lower airway inflammation in infants with cystic fibrosis detected by newborn screening. Pediatr Pulmonol. 2005;40(6):500-510.

43. Hartl D, Griese M, Kappler M, et al. Pulmonary $\mathrm{T}(\mathrm{H}) 2$ response in Pseudomonas aeruginosa-infected patients with cystic fibrosis. JAllergy Clin Immunol. 2006;117(1):204-211.

44. Downey DG, Martin SL, Dempster M, et al. The relationship of clinical and inflammatory markers to outcome in stable patients with cystic fibrosis. Pediatr Pulmonol. 2007;42(3):216-220.

45. Eagan TM, Gabazza EC, C DA-G, et al. TNF-alpha is associated with loss of lean body mass only in already cachectic COPD patients. Respir Res. 2012;18:13:48.

46. Levy H, Kalish LA, Huntington I, et al. Inflammatory markers of lung disease in adult patients with cystic fibrosis. Pediatr Pulmonol. 2007;42(3):256-262.

47. Long $\mathrm{H}, \mathrm{Luo} \mathrm{H}, \mathrm{Chen} \mathrm{P}, \mathrm{Li}$ Y. Correlation among the levels of C-reactive protein and interleukin-18, quality of life, and lung function in patients with chronic obstructive pulmonary disease. Zhong Nan Da Xue Xue Bao Yi Xue Ban. 2011;36(11):1090-1096.

48. Tsang KW, Rutman A, Tanaka E, et al. Interaction of Pseudomonas aeruginosa with human respiratory mucosa in vitro. Eur Respir J. 1994;7(10):1746-1753.

49. Grimwood K. Airway microbiology and host defences in paediatric non-CF bronchiectasis. Paediatr Respir Rev. 2011;12(2):111-118.

50. Chotirmall SH, Branagan P, Gunaratnam C, McElvaney NG. Aspergillus/allergic bronchopulmonary aspergillosis in an Irish cystic fibrosis population: a diagnostically challenging entity. Respir Care. 2008;53(8):1035-1041.

51. Guyot N, Bergsson G, Butler MW, et al. Functional study of elafin cleaved by Pseudomonas aeruginosa metalloproteinases. Biol Chem. 2010;391(6):705-716.

52. Khan TZ, Wagener JS, Bost T, Martinez J, Accurso FJ, Riches DW. Early pulmonary inflammation in infants with cystic fibrosis. Am J Respir Crit Care Med. 1995;151(4):1075-1082.

53. Suter S, Schaad UB, Tegner H, Ohlsson K, Desgrandchamps D, Waldvogel FA. Levels of free granulocyte elastase in bronchial secretions from patients with cystic fibrosis: effect of antimicrobial treatment against Pseudomonas aeruginosa. J Infect Dis. 1986;153(5): 902-909.

54. Karakoc GB, Inal A, Yilmaz M, Altintas DU, Kendirli SG. Exhaled breath condensate MMP-9 levels in children with bronchiectasis. Pediatr Pulmonol. 2009;44(10):1010-1016.

55. Shamamian P, Schwartz JD, Pocock BJ, et al. Activation of progelatinase A (MMP-2) by neutrophil elastase, cathepsin G, and proteinase-3: a role for inflammatory cells in tumor invasion and angiogenesis. $J$ Cell Physiol. 2001;189(2):197-206.

56. Chakrabarti S, Patel KD. Matrix metalloproteinase-2 (MMP-2) and MMP-9 in pulmonary pathology. Exp Lung Res. 2005;31(6): 599-621.
57. Bonfield TL, Panuska JR, Konstan MW, et al. Inflammatory cytokines in cystic fibrosis lungs. Am J Respir Crit Care Med. 1995;152(6 Pt 1): 2111-2118.

58. Hilliard TN, Regamey N, Shute JK, et al. Airway remodelling in children with cystic fibrosis. Thorax. 2007;62(12):1074-1080.

59. Solic N, Wilson J, Wilson SJ, Shute JK. Endothelial activation and increased heparan sulfate expression in cystic fibrosis. Am J Respir Crit Care Med. 2005;172(7):892-898.

60. Khatri IA, Bhaskar KR, Lamont JT, Sajjan SU, Ho CK, Forstner J. Effect of chondroitinase $\mathrm{ABC}$ on purulent sputum from cystic fibrosis and other patients. Pediatr Res. 2003;53(4):619-627.

61. Rahmoune H, Lamblin G, Lafitte JJ, Galabert C, Filliat M, Roussel P. Chondroitin sulfate in sputum from patients with cystic fibrosis and chronic bronchitis. Am J Respir Cell Mol Biol. 1991;5(4):315-320.

62. Frevert CW, Kinsella MG, Vathanaprida C, et al. Binding of interleukin- 8 to heparan sulfate and chondroitin sulfate in lung tissue. Am J Respir Cell Mol Biol. 2003;28(4):464-472.

63. Reeves EP, Williamson M, O’Neill SJ, Greally P, McElvaney NG. Nebulised hypertonic saline decreases interleukin- 8 in sputum of patients with cystic fibrosis. Am J Respir Crit Care Med. 2011; 183(11):1517-1523.

64. Chan ED, Choi HS, Cool C, Accurso FJ, Fantuzzi G. Interleukin-18 expression in cystic fibrosis lungs. Chest. 2002;121(Suppl 3): $84 \mathrm{~S}-85 \mathrm{~S}$.

65. Hauber HP, Beyer IS, Meyer A, Pforte A. Decreased interleukin-18 expression in BAL cells and peripheral blood mononuclear cells in adult cystic fibrosis patients. J Cyst Fibros. 2004;3(2):129-131.

66. Kawakami K, Koguchi Y, Qureshi MH, et al. Reduced host resistance and Th1 response to Cryptococcus neoformans in interleukin-18 deficient mice. FEMS Microbiol Lett. 2000;186(1):121-126.

67. McElvaney NG, Hubbard RC, Birrer P, et al. Aerosol alpha 1-antitrypsin treatment for cystic fibrosis. Lancet. 1991;337(8738):392-394.

68. Griese M, Latzin P, Kappler M, et al. alpha1-Antitrypsin inhalation reduces airway inflammation in cystic fibrosis patients. Eur Respir J. 2007;29(2):240-250.

69. Knutsen AP, Hutchinson PS, Albers GM, Consolino J, Smick J, Kurup VP. Increased sensitivity to IL-4 in cystic fibrosis patients with allergic bronchopulmonary aspergillosis. Allergy. 2004;59(1):81-87.

70. Albert RK, Connett J, Bailey WC, et al. Azithromycin for prevention of exacerbations of COPD. N Engl J Med. 2011;365(8):689-698.

71. Hodge S, Hodge G, Jersmann H, et al. Azithromycin improves macrophage phagocytic function and expression of mannose receptor in chronic obstructive pulmonary disease. Am J Respir Crit Care Med. 2008;178(2):139-148.

72. Seemungal TA, Wilkinson TM, Hurst JR, Perera WR, Sapsford RJ, Wedzicha JA. Long-term erythromycin therapy is associated with decreased chronic obstructive pulmonary disease exacerbations. Am J Respir Crit Care Med. 2008;178(11):1139-1147.

73. Vos R, Vanaudenaerde BM, Verleden SE, et al. Anti-inflammatory and immunomodulatory properties of azithromycin involved in treatment and prevention of chronic lung allograft rejection. Transplantation. 2012;94(2):101-109.

74. Willems-Widyastuti A, Vanaudenaerde BM, Vos R, et al. Azithromycin attenuates fibroblast growth factors induced vascular endothelial growth factor via p38(MAPK) signaling in human airway smooth muscle cells. Cell Biochem Biophys. December 29, 2011. [Epub ahead of print.]

75. Wong C, Jayaram L, Karalus N, et al. Azithromycin for prevention of exacerbations in non-cystic fibrosis bronchiectasis (EMBRACE): a randomised, double-blind, placebo-controlled trial. Lancet. 2012;380(9842):660-667. 
Journal of Inflammation Research

\section{Publish your work in this journal}

The Journal of Inflammation Research is an international, peer-reviewed open-access journal that welcomes laboratory and clinical findings on the molecular basis, cell biology and pharmacology of inflammation including original research, reviews, symposium reports, hypothesis formation and commentaries on: acute/chronic inflammation; mediators of inflammation;
Dovepress

cellular processes; molecular mechanisms; pharmacology and novel antiinflammatory drugs; clinical conditions involving inflammation. The manuscript management system is completely online and includes a very quick and fair peer-review system. Visit http://www.dovepress.com/ testimonials.php to read real quotes from published authors.

\footnotetext{
Submit your manuscript here: http://www.dovepress.com/journal-of-inflammation-research-journal
} 